\title{
Parametric Urban Design from Concept to Practice
}

\author{
Nicolai Steinø ${ }^{1}$ \\ ${ }^{I}$ Aalborg University, Department of Architecture, Design and Media Technology \\ ${ }^{1}$ steino@create.aau.dk
}

Little research has been made into the application of parametric urban design approaches to urban design in practice. On the part of urban design practitioners, lack of knowledge of parametric design, time constraints and a focus on day-to-day operations contribute to this situation. And on the part of parametric design researchers, lack of understanding of practice workflows, project types and media output types also contribute. The limited interaction between academia and practice in itself constitutes a barrier to changing the situation. This paper presents some first results from a research project aiming to overcome this barrier. The research design involves a theoretical framework for parameterising site design on the level of site layout, building forms and facade schemas. It also involves an analysis of typical workflows from urban design practice, as well as of the types of media which are typically used to present urban design projects.

Keywords: parametric design, urban design, urban design practice, methodology, workflow

\section{INTRODUCTION}

Many forms of urban design are distinct from architectural design in that they do not have a clear audience, nor a tangible output. Rather, they act as communication media to communicate design intents to a multitude of stakeholders and interest groups. And as such, they typically define a set of loose design guidelines to be observed, rather than precise design specifications. This is true for many masterplans, urban redevelopment plans, as well as for district plans, whether for greenfield development or brownfield redevelopment.

Such plans therefore often work by exemplification, offering a host of examples of how the plan might be implemented, or by scenarios, offering different design alternatives to be implemented. They may also present sets of more abstract restrictions (i.e. build-to lines, building envelopes, land-use contingencies, etc.) which subsequent building designs must comply with.

Examples, scenarios and restrictions have traditionally been visualised by way of static graphics in the form of diagrams, projection drawings, perspective renderings, reference photos, etc. However, by the advent of parametric design software, more dynamic forms of visualisation have been made possible, both during the development and subsequent presentation of urban design.

\section{Research Outline}

Building on previous work on establishing a parametric urban design framework for site design, in- 
cluding the parametric design of site layouts, building envelopes and facades (Steinø \& Obeling 2014, Steinø 2017), this research gives an account of applying this framework to an actual urban design project for the design of a masterplan for a suburban residential area. In a form of action research, the researcher operated as a sub-consultant in collaboration with an established planning consultancy to implement a parametric urban design workflow. As such, the aim of the research was to test the parametric urban design framework in a practice setting, in order to understand its potential advantages and/or shortcomings in urban design practice.

Theoretically, a parametric urban design workflow has several advantages:

1. It enables the dynamic and interactive production of data output and geometric output (2D/3D models).

2. It enables iterative design cycles to facilitate design collaboration between design professionals.

3. It facilitates the dynamic generation of multiple design scenarios in the context of live scenario building at stakeholder workshops.

4. It allows for a more or less automated generation of a host of graphics from diagrams over projection drawings to perspective renderings with limited or no need for postprocessing.

5. It provides a pipeline for the generation of videos and VR experiences, based on procedurally generated $3 \mathrm{D}$ environments.

A parametric urban model is generated from parameters which are set to specific values. Thus, the model can easily be modified by changing the values. As data (i.e. no. of dwellings, floor area ratios, land use by area, etc.) is linked to geometry, this allows for easy evaluation of different design scenarios against their associated data. This radically enhances design evaluation, as separate calculations are no longer necessary for each design iteration. This is highly relevant in urban design practice, where specific values must typically be met for different design criteria (parameters).

Different design professionals (i.e. architects, landscape architects, traffic and urban planners) focus on different aspects of urban design. A parametric model can easily be changed and is therefore capable of mediating the different design criteria of different design professionals in real time, through iterative design cycles.

In participatory design processes, lay person stakeholders are typically presented with 2-3 design scenarios as a basis for discussion. While the criteria defining the different scenarios are often oblique (as they have been predefined by the design professionals), scenarios are a practical necessity by conventional means of design. With parametric urban design however, the design may be altered through live scenario building, allowing for multiple design scenarios.

By conventional design methods, the production pipeline for the final graphics communicating the design may comprise a number of different graphic and CAD software applications. In addition, final graphics must be altered manually whenever last-minute alterations to the design are made. This results in reduced efficiency and high time pressure towards the end of the design process. As imperfect knowledge often leads to late alterations to the design in urban design, this is a likely scenario.

By a parametric urban design approach, the parametric urban model can be designed to automatically output different types of graphics, from diagrams over projection drawings to perspective renderings. Thus, it is capable of reflecting last-minute design alterations with no or limited extra effort.

Finally, with the advent of new game engine software such as Unity and Unreal Engine, new possibilities have emerged for the effortless generation of videos and VR experiences from parametric urban models. As a parametric urban model may be generated with a high level of detail with little effort, the work which is embedded in it may easily be used to provide a pipeline for the generation of videos and 
Figure 1

User participation workshop. The parametric urban design model is visible on the screen

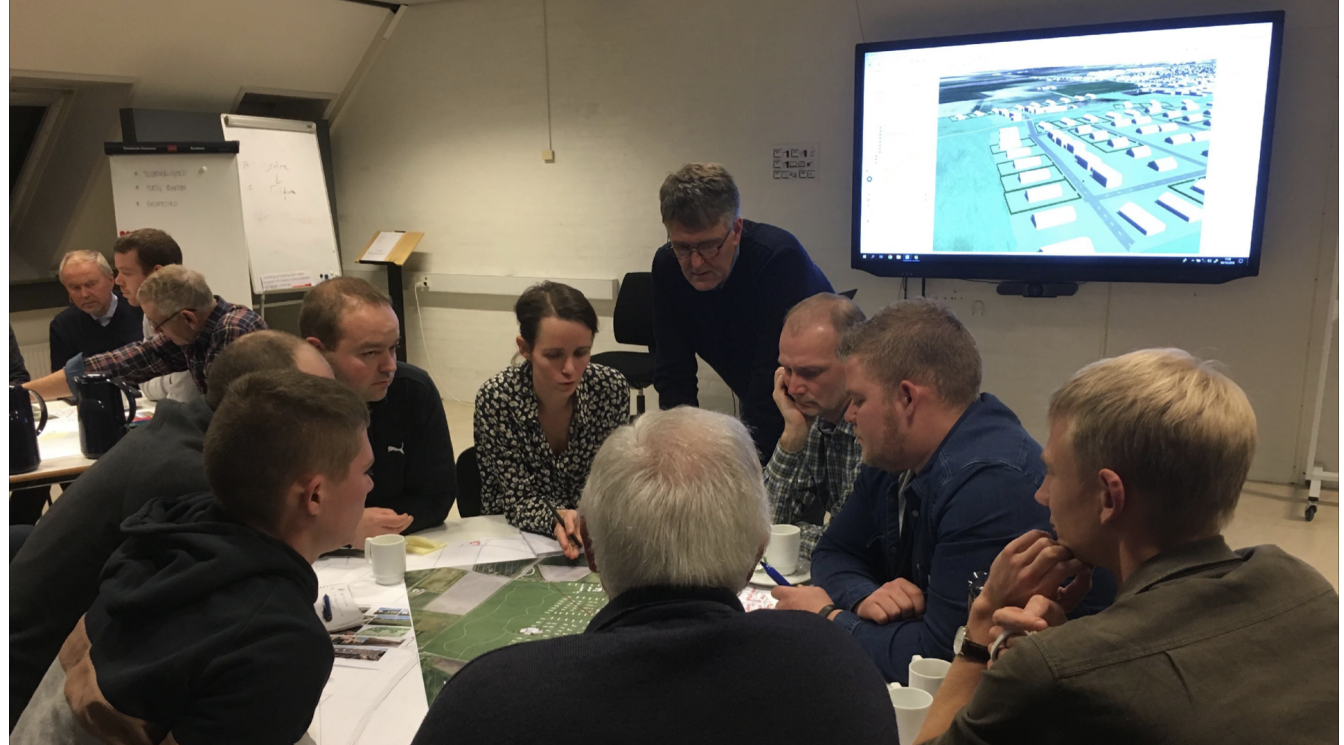

VR experiences. Video and VR represent new and enhanced modes of representation for urban design, offering new possibilities of exploring and understanding the design at hand.

In total, the aim of the research has been to explore these five potential advantages of a parametric urban design workflow in urban design practice. This was unfolded in the framework of a test case in the form of a project for the design of an actual masterplan for a new residential area of a small town. The researcher's contribution to the project was carried out as a sub-consultancy to an established urban planning consultancy. This was done using a software framework encompassing the parametric urban modeling software CityEngine, the game engine software Unreal Engine, and Photoshop.

\section{Related Work}

Several studies have been made to develop a methodological framework for parametric urban design. Most notably, shape grammars have formed the basis for such work by Beirão, Duarte, Gil, Stouffs and others in the context of the City Induction project. This body of work on parametric urban design encompasses three areas of investigation, formulation, generation and evaluation, and focuses in part on flexibility and variation (Beirão \& Duarte 2005), GIS and spatial analysis (Gil \& Duarte 2008, Beirão et al. 2008), urban patterns and grammars (Beirão et al. 2009, 2010), and tool development (Beirão et al. 2011, 2012). Shape grammars are also the basis for Paio \& Turkienicz' $(2010,2011)$ analyses of historical Portuguese cities.

Different explorations have been made into the practical application of a parametric design approach to urban design and its related fields. Madkour et al. (2009) explore the application of parametric design to building design and city planning, while UImer et al. (2007) are interested in the application of parametric/procedural modeling to urban design and landscape planning. For their work, Ulmer et al. use CityEngine. This is also the platform used by 
Kunze et al. (2012) for their work on implementing design code building typologies in parametric/procedural urban modeling.

Parametric urban design has obvious potentials for participatory design processes. This has been addressed by Jacobi et al. (2009), Kunze et al. (2010, 2011, 2012) and by Steinø et al. (2013).

Practice application of interactive visualisation and parametric modeling for urban design may address both public planning and private consultancy. Not many such studies have been made, however. One exception in the area of public planning is Dobson \& Lancaric's (2003) somewhat older study for an interactive digital 3D urban model, which incorporates a variety of visual, graphic and numeric data to generate building scenarios to be presented online. Another exception is Schirmer \& Kawagishi's (2011) more recent investigation of the application of CityEngine in architectural consulting. In this case, parametric urban design was used for visualisation, the creation of random subdivisions, and for typological testing.

\section{METHODOLOGY}

The main focus of the presented research was to explore a software framework which enables a fast and flexible workflow for a host of urban design tasks from massing studies to masterplans, capable of producing a variety of media types, from massing models and figure/ground maps, over land use maps and traffic diagrams, to detailed site plans and perspective renderings, all from the same parametric model. In addition to these traditional media types, the ambition was to use the parametric model for live scenario building at stakeholder workshops, as well as for animation videos and VR.

Based on previous research (Steinø \& Obeling 2014, Steinø 2017), a small case study was conducted in order to analyse and classify typical site designs, building forms and facade schemas respectively for the specific task. From this analysis, scripts were coded to parametrically control variations to the design on these three levels. While still in its infancy, this body of code is capable of producing a large number of different site designs with architectural detailing, although not yet able to offer enough flexibility to cater for most desired design variations.

An important objective of the project has been to keep the software framework simple, in order to maintain the efficiency of the workflow. Hence, it was limited to:

- CityEngine for parametric modeling using the cga scripting language

- Unreal Engine for physics-based rendering and animation

- Photoshop for retouching and adding high detail single objects to renderings

For CityEngine, the input used is open GIS data in the form of 2D building polygons, street centerlines and terrain rasters, and cga scripts for model and data generation. The output from CityEngine is 3D models, 2D maps, data (floor areas, floor area ratios, land use, no. of dwellings, no. of parking spaces, etc.), and 360 VR images. For Unreal Engine, the input used is the 3D models generated in CityEngine, as well as various textures and other model assets. The output from Unreal Engine is rendered site plans, perspective views (stills) and video animations. For Photoshop, both the input (from Unreal Engine) and the output is rendered images.

Design revisions are a recurring element in all phases of design practice. Ideally, the design model should therefore remain in the parametric modeller (in this case CityEngine) for as long as possible to allow for parametric modification. However, as the render functionality of CityEngine is currently substandard, another software (in this case Unreal Engine) is used to this end. However, more diagrammatic media types such as land use and figure/ground maps may still be rendered satisfactorily in CityEngine, leaving only a subset of the required media types to be finalised in Unreal Engine. 
Figure 2

Mock-up

parametric

masterplan

Figure 3

Figure 4

Figure 5

Hand sketch

produced by the main consultant
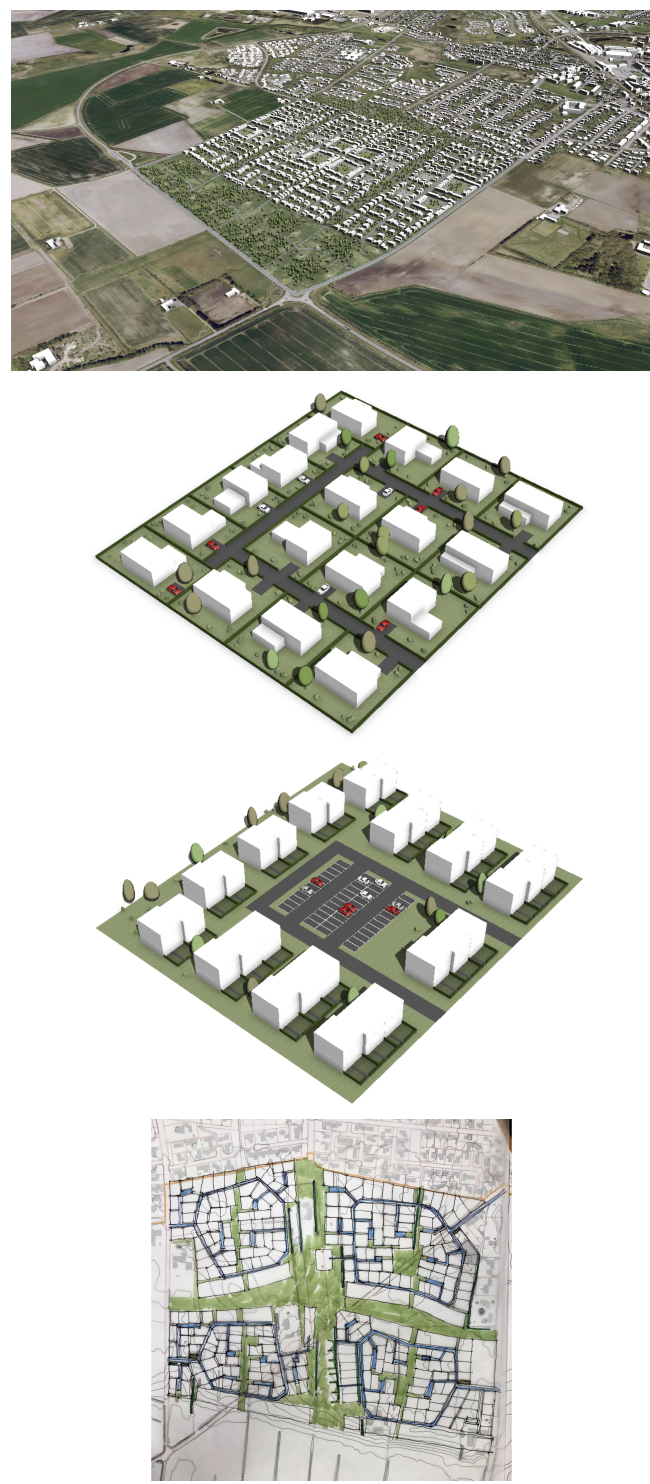

\section{TEST CASE RESULTS}

The methodological framework described above was put to use for the design of a masterplan for a new suburban residential area of a small municipal town in the Northern part of Denmark. The parametric design work was carried out as a sub-consultancy to a planning consultancy who was commissioned by the municipality to develop the masterplan. The lead professionals involved from the planning consultancy were a land surveyor (project manager) and an architect. As part of the design process, a series of meetings were held with professionals from the municipality, as well as two user participation workshops with landowners from the affected areas (fig. 1).

The aim of the collaboration was to use parametric design to test and ultimately visualise

- The overall masterplan in the context of existing development

- A detailed site plan with building types, greenspaces with vegetation elements (trees and hedges)

- Possible variations of building typologies in select parts of the masterplan

- Development phase diagrams

- A birds eye perspective rendering of the entire development area

- A number of perspective renderings of prototypical elements of the masterplan

Prior to the design process, the researcher/subconsultant presented a mock-up parametric masterplan (Fig. 2) and conceptual designs for different subdivision schemes (Fig. 3 and 4) to the main consultant, in order to introduce the principles of parametric urban design and their possible application to the project to the main consultant. The advantages of the parametric urban design approach, including the linkage between 3D model and data, as well as the automated generation of final graphics were explained and discussed.

In the course of the design process, hand sketches were produced by the main consultant as a basis for the parametric design work (Fig. 5). Pre- 
liminary renderings of the parametric model were returned for discussion and further design development, in part to evaluate different design alternatives, such as the width and shape of a public green space (Fig. 6-8). For the first user participation workshop, a preliminary parametric 3D model was used for live scenario building to analyse and discuss different design alternatives (Fig .1). Once the design was near completion, the parametric model was migrated into Unreal Engine and some preliminary renderings were produced and presented to the main consultant to discuss and adjust the render quality. On this basis, graphics showing design variations (Fig. 9-11) and perspective renderings were produced in Unreal Engine.

A small video animation (not shown) was also produced for internal purposes to test this part of the workflow. While not part of the planned scope of work, the video was shared with the main consultant and ultimately shown at the second user participation workshop. Once the design was finalised, the described graphics were produced in CityEngine and Unreal Engine respectively. Some post-processing was done in Photoshop to some of the graphics, for retouching and adding high detail objects (Fig. 1213).

While most of the final graphics could have been produced using the devised workflow, the main consultant chose to ultimately produce some graphics manually. Miscommunications based on an insufficient understanding of the parametric workflow on behalf of the project manager led to some frustration, as unexpected requirements for new types of graphics were introduced at a late stage in the process. In addition, the project manager was unhappy with the quality of some final graphics produced using the parametric workflow.

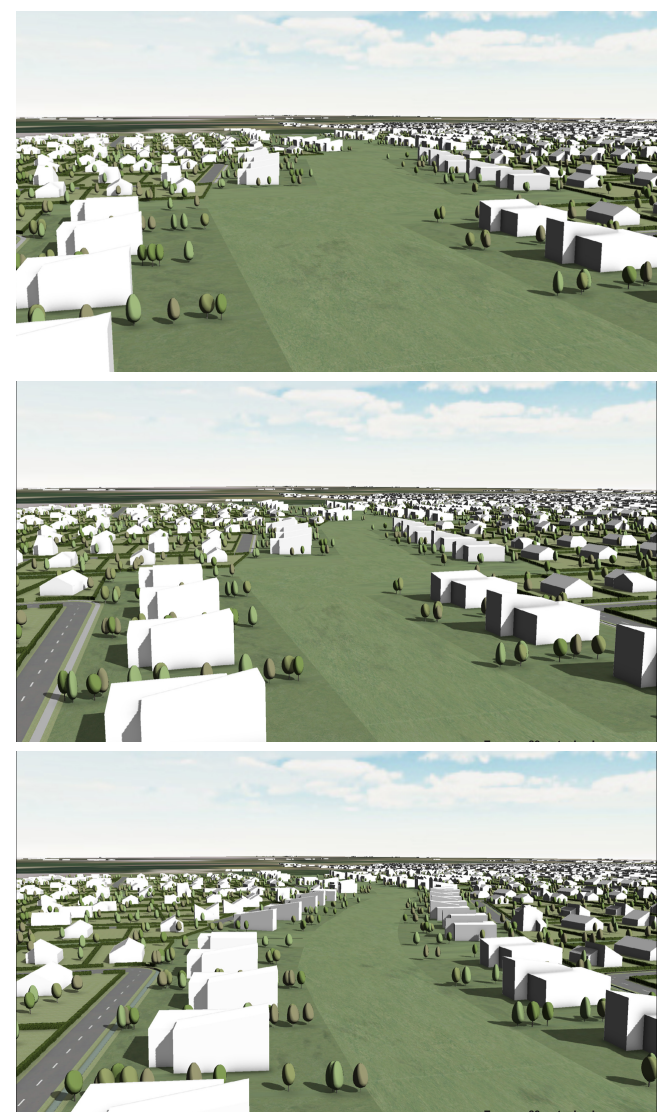

Figure 6

Figure 7

Figure 8

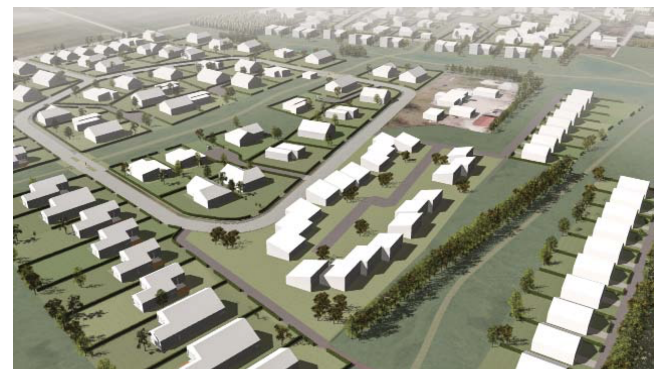

Figure 9 
Figure 10

Figure 11

Figure 12

Figure 13
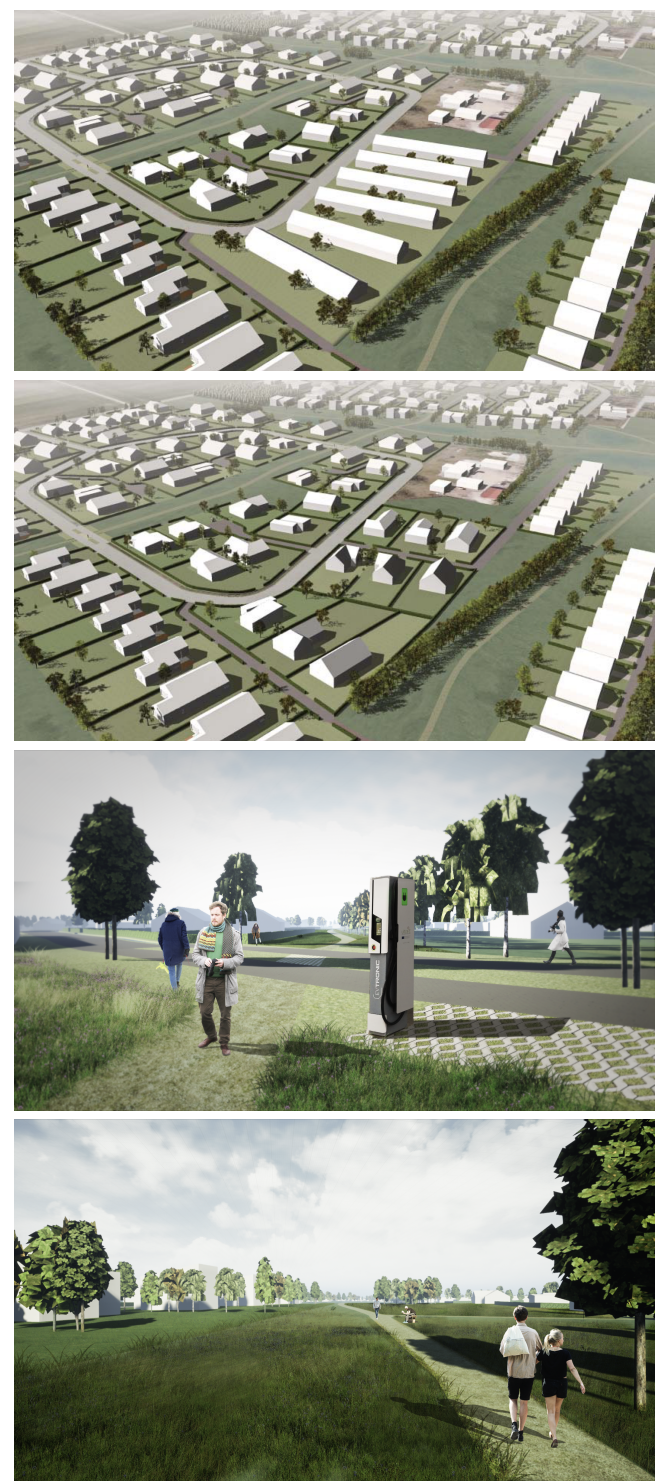

Hence, while the workflow was carried out largely as planned, some additional graphics - the video animation - were made in addition to the agreed scope of work, while other graphics were ultimately rejected. And while some additional graphics could not be produced as they had not been planned as part of the workflow, an original idea to use VR during the first user participation workshop was abandoned. The latter was due to the project manager being uneasy about the value of VR in this context, as this was a technology which was unfamiliar to him.

\section{DISCUSSION}

As a professional activity, urban design practice is based on sets of best practice, established forms of collaboration and output conventions. Depending on the project type - i.e. massing or visibility studies, site designs, masterplans - urban design professionals typically work from past experiences which they adapt to the task at hand. As different project types require different sets of expertise, different professionals - i.e. architects, engineers, urban planners may be involved in the process. And once the work is done, it is presented to the client (whether private or public), typically in the form of reports with text and graphics.

Urban design graphics range from abstract diagrams (showing circulation, green space, density, etc.) over projection drawings (plans, sections, elevations) to perspective renderings with varying degrees of photo realism. Such graphics are typically made using a range of graphic and CAD software, often in sequence in some form of software framework. Whether developed from conventional hand sketches or simulation software, such graphics are based on input from the different professionals involved in the proces.

As such, urban design practice represents an ecosystem of practices, professionals and graphics, based on conventions established through experience. Hence, introducing parametric urban design methods is not a matter of simply adding another tool to the toolbox. It is likely to impact all elements of this ecosystem, as it not only introduces more 'efficient' ways of working, but potentially changes both established practices, forms of collaboration and out- 


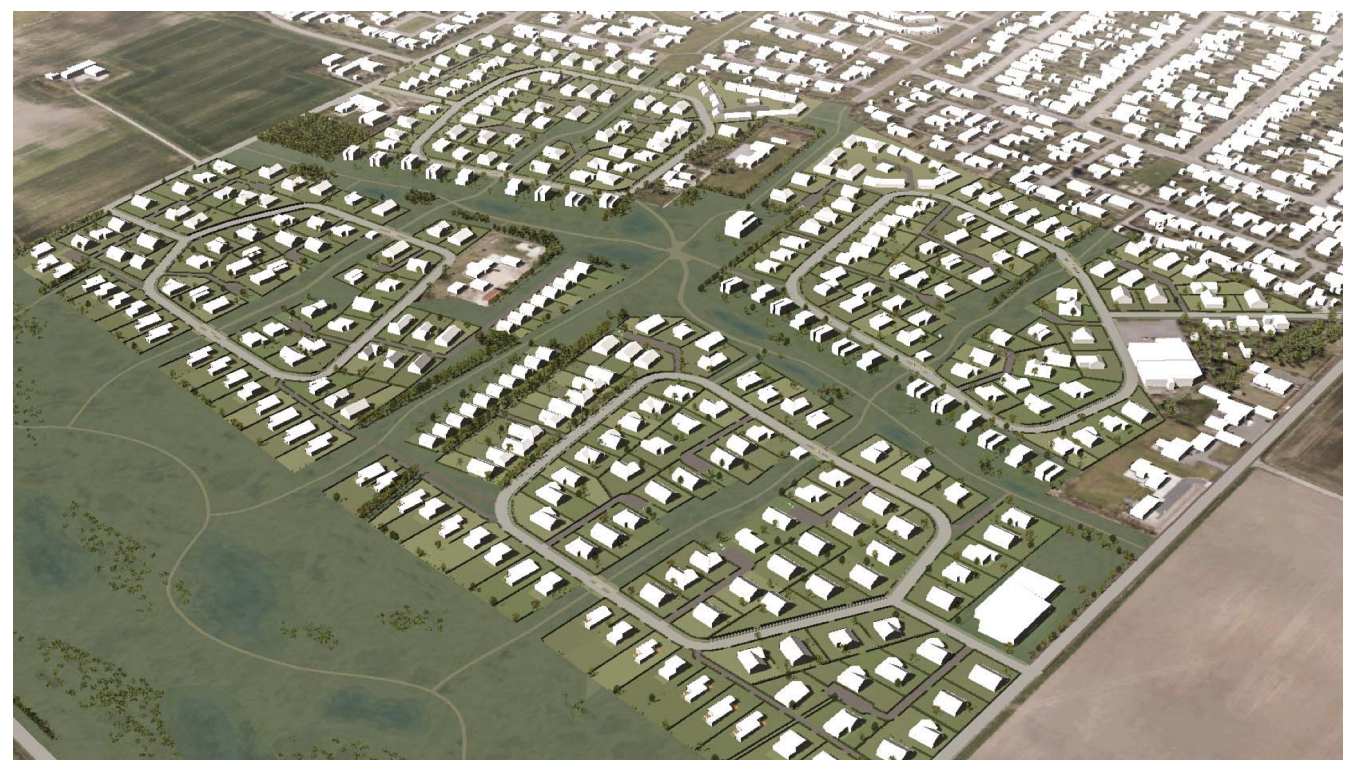

Figure 14

Final masterplan

perspective

rendering.

Compare fig. 2 and

5

put types. In other words, it is likely to disrupt the very professional culture of urban design practice.

This became evident in the test case presented here. The project manager initially envisioned parametric urban design as a form of design optimisation tool. Given the large amount of potential parameters and variables, this is (as of yet) not feasible in urban design. It took some explaining to establish a more realistic understanding with the project manager as to the potential of parametric urban design. That is, that while the overall design principle still needs to be conceived architecturally by a human designer, the parametric model may, one the one hand, generate associated data (no. of dwellings, floor area ratios, land use by area, etc.) for design evaluation and, on the other hand, generate variations of the design based on the parameters which have been incorporated for design iteration.

The generation of associated data within the parametric urban design model seemed to the researcher/sub-contractor as one of the main 'sell- ing points' of a parametric urban design approach. During the design process, the researcher/subcontractor provided a range of data with the 3D models and asked whether they were relevant. However, the main contractor did not respond to this and never seemed to take much interest in this data, despite the fact that it was information which had influence on the plan and which had to be submitted as part of the contract and therefore ended up being produced manually.

\section{CONCLUSION}

The action research case study accounted for in this paper put a methodological framework for parametric urban design to test in a real-life setting in collaboration with a professional planning consultancy. The framework was designed on the basis of anticipations about the task at hand and presented to the main consultant at the beginning of the process. While parts of the framework proved to work, others did not. The unsuccessful parts of the framework 
failed in part due to misconceptions about the nature of the parametric workflow on behalf of the project manager, and in part due to the researcher/subcontractor failing to meet the graphic aspirations of the main consultant. And while an animation video was produced and used which was not part of the planned scope of work, diagrams which were originally planned were ultimately produced manually.

As a form of action research, the case study was based on the premise that the main consultant ultimately had to deliver a professional product to his client. In the project manager's judgment, this required parts of the work to be produced using conventional techniques. This was true, both for some graphics and for the choice of not introducing VR at the user participation workshop.

In conclusion, both the main consultant and the sub-consultant/researcher bore parts of the responsibility for this result. While the main consultant did not quite understand parts of the methodological framework (the nature of the workflow, the value of associated data) and did not have confidence in the value of VR for participatory processes. The subcontractor/researcher on the other hand, failed to deliver satisfactory graphics for diagrams. He also failed to demonstrate VR in action to the main contractor and hence to illustrate its potential.

Despite these failures, the overall results were successful. It was shown that a parametric urban design workflow is in fact functional and does produce several of its theoretical advantages. Design alterations could in fact be incorporated even late in the design process, without causing significant extra work. Relevant associated data could in fact be produced even if it was not taken into consideration. And a workflow from CityEngine into Unreal Engine could in fact be put to use with very little effort, in order to produce an animation video.

\section{ACKNOWLEDGEMENTS}

The author would like to thank urban designer Kristian Mortensen and student intern Sarah Lassen who worked with him in his consultancy CityPeople for their hard work and dedication to the project. He would also like to thank Claus Otto Nielsen at Niras Consulting for having trust in hiring him as a subconsultant on parametric urban design for the development of the masterplan for Brønderslev Syd, Denmark.

\section{REFERENCES}

Beirão, J 2012 'Parametric Urban Design: Joining morphology and urban indicators in a single interactive model', Digital Physicality: Proceedings of the 30th eCAADe Conference, Prague, p. 167

Beirão, J and Duarte, J 2005 'Urban Grammars: Towards Flexible Urban Design', Digital Design: The Quest for New Paradigms: 23rd eCAADe Conference Proceedings, Lisbon, p. 491

Beirão, J, Duarte, J and Stouffs, R 2008 'Structuring a Generative Model for Urban Design: Linking GIS to Shape Grammars', Architecture 'in computro' - Integrating Methods and Techniques: 26th eCAADe Conference Proceedings, Antwerp, p. 929

Beirão, J, Duarte, J and Stouffs, R 2009 'Grammars of designs and grammars for designing - grammar-based patterns for urban design', Joining Languages, Cultures and Visions: Proceedings of the 13th International CAAD Futures Conference, Montréal

Beirão, J, Mendes, G, Duarte, J and Stouffs, R 2010 'Implementing a Generative Urban Design Model: Grammar-based design patterns for urban design', Future cities: 28th eCAADe Conference Proceedings, Zurich, p. 265

Beirão, J, Nourian, P and Mashhoodi, B 2011 'Parametric urban design: an interactive sketching system for shaping neighborhoods', Respecting Fragile Places: 29th eCAADe Conference Proceedings, Ljubljana, Slovenia, pp. 225-234

Dobson, A and Lancaric, P 2003 'VIRTUreALITY Digital Urban Modelling as a Community Design Form', Connecting " Crossroads of Digital Discourse: Proceedings of the 2003 Annual Conference of the Association for Computer Aided Design in Architecture, ACADIA, Indianapolis, p. 49

Gil, J and Duarte, J 2008 'Towards an Urban Design Evaluation Framework', Architecture 'in computro' - Integrating Methods and Techniques: 26th eCAADe Conference Proceedings, Antwerp, p. 257

Jacobi, MM, Halatsch, J, Kunze, A, Schmitt, G and Turkienicz, B 2009 'A grammar-based system for the participatory design of urban structures', SIGraDi 
2009 - Proceedings of the 13th Congress of the Iberoamerican Society of Digital Graphics, Sao Paulo, pp. 16-18

Kunze, A, Dyllong, J, Halatsch, J, Waddell, P and Schmitt, G 2012 'Parametric Building Typologies for San Francisco Bay Area: A conceptual framework for the implementation of design code building typologies towards a parametric procedural city model', Digital Physicality: Proceedings of the 30th eCAADe Conference, Prague, p. 187

Kunze, A, Halatsch, J, Vanegas, C, Jacobi, MM, Turkienicz, B and Schmitt, G 2011 'A Conceptual Participatory Design Framework for Urban Planning: The case study workshop 'World Cup 2014 Urban Scenarios', Porto Alegre, Brazil', Proceedings of the eCAADe Conference, Ljubljana, pp. 895-903

Kunze, A and Schmitt, G 2010 'A Conceptual Framework for the Formulation of Stakeholder Requirements', Future cities: 28th eCAADe Conference Proceedings, Zurich, p. 697

Madkour, Y, Neumann, O and Erhan, H 2009, 'Programmatic Formation: Practical Applications of Parametric Design', International Journal of Architectural Computing, 7(4), pp. 587-604

Paio, A and Turkienicz, B 2010 'A Grammar for Portuguese Historical Urban Design', Future cities: 28th eCAADe Conference Proceedings, Zurich, p. 349

Paio, A and Turkienicz, B 2011, 'An Urban Grammar Study: A Geometric Method for Generating Planimetric Proportional and Symmetrical Systems', Nexus Network Journal, pp. 151-169

Schirmer, P and Kawagishi, N 2011 'Using Shape Grammars as a Rule Based Approach in Urban Planning a Report on Practice', Respecting Fragile Places: 29th eCAADe Conference Proceedings, Ljubljana, p. 116

Steinø, N 2017 'Mapping the Architectural Genome: A Preliminary Study of Facade Syntax', ShoCK! - Sharing Computational Knowledge!: Proceedings of the 35th eCAADe Conference, Rome, p. 453

Steinø, N and Obeling, E 2014, 'Developing a Parametric Urban Design Tool : Some Structural and Organizational Challenges and Possible Ways to Overcome Them', Architecturae et Artibus, 6(1), p. 51

Steinø, N, Yıldırım, MB and Özkar, M 2013 'Parametric Design Strategies for Collaborative Urban Design', Computation and Performance - Proceedings of the 31st eCAADe Conference, Delft, p. 195

Ulmer, A, Halatsch, J, Kunze, A, Müller, P and Gool, LV 2007 'Procedural Design of Urban Open Spaces', Predicting the Future: 25th eCAADe Conference Proceedings, Frankfurt am Main, p. 351 